\title{
Correction to: Surgery due to mechanical bowel obstruction in relapsed ovarian cancer: clinical and surgical results of a bicentric analysis of 87 patients
}

\author{
R. Armbrust ${ }^{1} \cdot$ R. Chekerov ${ }^{1} \cdot$ S. Sander ${ }^{1} \cdot$ M. Biebl ${ }^{2} \cdot$ S. Chopra ${ }^{2} \cdot$ Jonathan Krell $^{3} \cdot$ Natasha Rinne $^{3} \cdot$ Katherine Nixon $^{3}$. \\ C. Fotopoulou ${ }^{3} \cdot$ J. Sehouli ${ }^{1}$
}

Published online: 22 November 2021

(c) The Author(s) 2021

\section{Correction to: Archives of Gynecology and Obstetrics https://doi.org/10.1007/s00404-021-06237-x}

In the original article published, the Fig. 2 is published incorrectly. The correct figure is given below.

The original article has been corrected.

The original article can be found online at https://doi.org/10.1007/ s00404-021-06237-x.

R. Armbrust

robert.armbrust@charite.de

Department of Gynecology with Center for Oncological

Surgery, Charité-University Hospital Berlin, Augustenburger

Platz 1, 13353 Berlin, Germany
Department of Surgery, Charité-University Hospital Berlin, Berlin, Germany

3 West London Gynecological Cancer Centre, Imperial College NHS Trust, London, UK 
Fig. 2 Overall survival in days from initial diagnosis

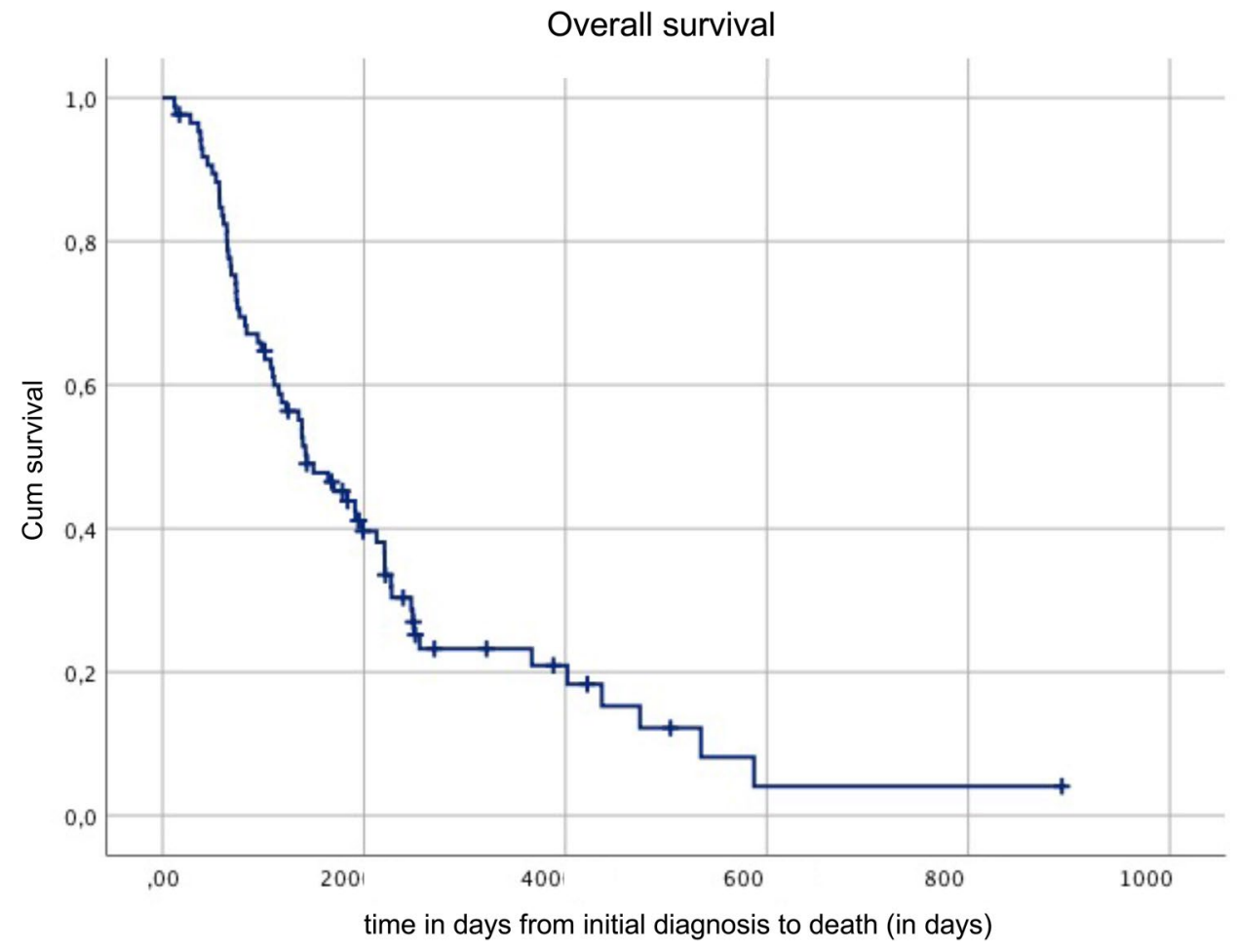

Open Access This article is licensed under a Creative Commons Attribution 4.0 International License, which permits use, sharing, adaptation, distribution and reproduction in any medium or format, as long as you give appropriate credit to the original author(s) and the source, provide a link to the Creative Commons licence, and indicate if changes were made. The images or other third party material in this article are included in the article's Creative Commons licence, unless indicated otherwise in a credit line to the material. If material is not included in the article's Creative Commons licence and your intended use is not permitted by statutory regulation or exceeds the permitted use, you will need to obtain permission directly from the copyright holder. To view a copy of this licence, visit http://creativecommons.org/licenses/by/4.0/.
Publisher's Note Springer Nature remains neutral with regard to jurisdictional claims in published maps and institutional affiliations. 